\title{
Heavy metals in road deposited sediments and road dusts of Colombo Capital, Sri Lanka
}

\author{
Dilmi Herath ${ }^{1,2}$, Amarasooriya Pitawala ${ }^{1,2^{*}}$ and Jagath Gunatilake ${ }^{1,2}$ \\ ${ }^{I}$ Department of Geology, Faculty of Science, University of Peradeniya, Peradeniya. \\ ${ }^{2}$ Postgraduate Institute of Science, University of Peradeniya, Peradeniya.
}

\begin{abstract}
Road deposited sediment (RDS) and road dust analyses are useful techniques to understand the heavy metal (HM) pollution in an urban area. Therefore, this study focused on the chemical characteristics of RDS and road dust in order to evaluate the pollution conditions in the Colombo Metropolitan Region (CMR) in terms of HMs. Forty six (46) RDS samples and forty eight (48) road dust samples were collected, and elemental concentrations of $\mathrm{Zn}, \mathrm{Cu}, \mathrm{Pb}, \mathrm{Fe}, \mathrm{Mn}$ and $\mathrm{Cr}$ were determined. Out of these measured elements, the most abundant element in all the samples was Fe, which is a common element in the basement lateritic soil in the area. $\mathrm{Cu}, \mathrm{Pb}, \mathrm{Fe}$ and $\mathrm{Cr}$ concentrations in RDS are high in industrial areas, while $\mathrm{Zn}$ and $\mathrm{Mn}$ are high in commercial areas. Except Fe, all the other element levels were higher in road dust than in RDS. Data analysis revealed that vehicle-related activities are the dominant source for the metals in the city. $\mathrm{Zn}, \mathrm{Cu}, \mathrm{Mn}$ and $\mathrm{Fe}$ contents were significantly higher than the background levels of the area. Statistical analysis reconfirms that road dust is more polluted than RDS in terms of $\mathrm{Zn}$ and $\mathrm{Cu}$. According to the geoaccumulation index, road dust is moderate to strongly polluted and RDS are moderately polluted. Higher pollution conditions of road dust may be due to the resuspension of dust particles. Spatial distribution patterns show that HMs of anthropogenic origin were accumulated towards the North and Northwestern parts where the transportation related activities are centered in the CMR. However, the prevailing natural conditions such as wind direction, geomorphology and basement soil also control the level of contamination in the area.
\end{abstract}

Keywords: Dust, heavy metals, pollution, sediments, urban.

\section{INTRODUCTION}

Environmental pollution is a persistent problem for many urban cities in the world. As a result, millions of people living in and around urban centers are exposed to an unnatural and unhealthy environment, which may cause a serious threat to human health as well as for the environment. The common environmental pollutants are aromatic compounds (Ray et al., 2008; Mostafa et al., 2009), heavy metals (Birch \& Scollen, 2003; Ahmed \& Ishiga, 2006; Wei \& Yang, 2010) and particles of minerals and fibers (Whittaker et al., 2003; Bruni et al., 2006).

Heavy metals are essential for vital processes in humans and many living organisms (Guney et al., 2010). However, they have a great ecological significance today due to their toxicity and accumulative behaviour (Hoque et al., 2011). These can accumulate in the body, affect the central nervous system, cause poisoning, and act as co-factors in many other illnesses (Tume et al., 2008). Therefore, the determination of heavy metal pollution in urban areas and the investigation of its sources are important to reduce the pollution effectively (Kabadayi \& Cesur, 2010).

Pollution from overland transportation is an inevitable environmental consequence of increasing commercial and industrial activities in developing areas (Guney et al., 2010). Lead (Pb), $\mathrm{Cu}$ and $\mathrm{Zn}$, are the most common elements accumulated by transportation through gasoline, wearing of vehicle parts and oil lubricants (Alloway \& Alloway, 1995; Li et al., 2001; Ahmed et al., 2007). These metals are deposited in the form of dust and can form aerosols to which everyone can be exposed (Guney et al., 2010). The use of large number of old vehicles, poor maintenance of high traffic congestion due to unorganised road networks, poor conditions of roads, construction activities and improper waste disposal methods are common unfriendly environmental practices in developing countries, which can affect the heavy metal contamination in an area. 
Road deposited sediments (RDS) are an accumulation of particles on pavements or edges of the roads in urban environments (Robertson \& Taylor, 2007), while dusts deposited on road surfaces are usually called road dusts or street dusts (Wei et al., 2010). Both RDS and road dusts can act as significant pollution sources, specially when stormwater runoff removes large parts of these together with associated metals, causing a pollution threat to receiving surface waterbodies and sub-surface water resources (Singh, 2011). Therefore, the analyses of RDS and road dust are useful to understand the heavy metal pollution of an urban area (Li et al., 2001).

The interaction of metals with naturally occurring organic matter (OM) plays an important role in determining the function of these metals in soil and water (Ongeri et al., 2010). A high percentage of OM in sediments contributes significantly to the bioavailability of heavy metals in sediments (Ongeri et al., 2010), because $\mathrm{OM}$ provides binding sites for metal ions influencing their bioavailability, toxicity and transport behaviour.

Pollution levels of heavy metals in RDS and road dust are assessed by different statistical methods. The commonly used methods are correlation analysis, enrichment factor (EF) and geoaccumulation index $\left(\mathrm{I}_{\text {geo }}\right)$ (Lu \& Bai, 2010; Hoque et al., 2011; Singh, 2011). In order to establish inter-element relationships in collected samples, correlation coefficient analysis proves to be a useful tool (Kabadayi \& Cesur, 2010). The main factors behind enrichment of metals are change in land-use patterns and lithological effects besides anthropogenic pressure (Hoque et al., 2011).

The impact of air pollution on human health has become a major issue in Sri Lanka because respiratory system related illnesses are ranked as the $2^{\text {nd }}$ leading cause of hospitalisation in the country (Elangasinghe \& Shanthini, 2009). Therefore, many studies have been conducted on air pollution (Ileperuma, 2000; Senarath, 2003; Pitawala et al., 2013). Studies on the particulate matter of air in the urban environment of Sri Lanka have been limited (Seneviratne et al., 1999) although this material may contain many toxic constituents (Ileperuma, 2000; Senarath, 2003). Due to rapid development and increasing number of vehicles on the road in the recent past, there is a high possibility for the pollution of urban environment in the country. Also the prevailing natural conditions such as high humidity, influence of the sea on corrosion, wind and undulated morphological setting of major cities of the coastal area can facilitate accumulation of toxic material in the environment (Pitawala et al., 2013).
There is a high possibility of contaminants accumulating in cities of the country. However, the pollution conditions of dust and sediments in such environments have not yet been evaluated. Therefore, this study (1) investigates the chemical characteristics of RDS and road dust from three different land-use areas, (2) identifies possible sources of heavy metal pollution and (3) seeks to understand the spatial distribution of heavy metals in road dust in the Colombo Metropolitan Region (CMR).

\section{Study area}

Colombo is the commercial capital of Sri Lanka, which is located along the Western coast of the country. Out of 20 million people in the country, $11 \%$ live in Colombo and they use $40 \%$ of the total vehicles within the city (Department of Census and Statistics, 2011). A large number of small to medium scale industries are operated in the Ratmalana area in the CMR, intermixed with residential and commercial establishments. The predominant industries include textile, chemical, metal, mineral-based and food industries (De Alwis et al., 1994).

Particulate pollution in the Colombo city center is mainly from vehicular emissions and soil dust movement (Senarath, 2003). Therefore the city center area, where commercial activities are dominant, was selected to investigate the road dust pollution in this study. Both bus and railway transportation for the public are concentrated in the Colombo city center. The traffic flows crossing the city increased at a rate of $5.4 \%$ per annum over the last two decades. The passenger growth is about $4.7 \%$ (Kumarage, 2007). Most residential settlements in the Colombo District prefer the suburban areas away from the city center.

The CMR covers an area of $37 \mathrm{~km}^{2}$ and a mostly flat area of land. High humidity $(75-95 \%)$ and an average annual rainfall of 2,400 $\mathrm{mm}$ are characteristic conditions, with a mean annual temperature of approximately $28{ }^{\circ} \mathrm{C}$ with a slight variation in mean monthly temperatures (Department of Meteorology, 2013). The wind flow into the city varies depending on monsoonal conditions. Wind mainly flows from the Northwestern direction (from the seaside) and moves across the city towards the central parts of the country. The overburden soil cover is predominated by lateritic soil formed due to intensive weathering of basement rocks and peaty soil derived from marshy environments (Cooray, 1984). 


\section{METHODOLOGY}

\section{Sampling}

Forty six (46) RDS samples and forty-eight (48) road dust samples were collected within the CMR during the dry period following at least one rainless month. Rain has no effect on the trace metals accumulated in these months. For the collection of RDS, sample sites were selected considering the intensity of commercial and industrial activities as well as the density of residential land-use. The industrialised Ratmalana area, Colombo city center as being commercialised area and residential areas in the small cities near the city center were selected for the sampling sets (Figure 1a). Most of the road dust samples were collected from the areas within the city center and the surroundings (Figure 1b). Since some building constructions are being carried out in other locations, the dust generated from such places may also accumulate into the road dust. Therefore, such areas were ignored for the sampling collection. Further, the roads were not cleaned regularly in the industrial and residential areas. Thus the accumulation time of dust is high, and it was assumed that more representative samples can be obtained from the commercial areas. RDS samples were collected from the edges of the roads by using a hand shovel and road dust samples were collected by sweeping nearly a $1 \mathrm{~m}^{2}$ area using a plastic brush and a dust pan into polythene bags. At each sampling point, three sub-samples were taken and then mixed to obtain a bulk sample. Such a sampling strategy was adopted in order to reduce the possibility of random influence of urban waste that is not clearly visible. The current study adopted a similar sampling strategy as in the literature (Birch \& Scollen, 2003; Ahmed \& Ishiga, 2006; Zhu et al., 2008; Singh, 2011). Both types of samples were transported to the laboratory for further analyses.

\section{Laboratory analysis}

Samples were dried, sieved (sieve size $0.63 \mathrm{~mm}$ ) and the pan fraction was selected. The OM content of all sediment and dust samples was measured by loss on ignition method. The samples were weighed to $1 \pm 0.01 \mathrm{~g}$, oven dried at $105{ }^{\circ} \mathrm{C}$ overnight and reweighed prior to ignition in furnace at $450{ }^{\circ} \mathrm{C}$ for $4 \mathrm{hrs}$. These were then cooled to room temperature in a desiccator. The percentage dry weight loss was taken as an estimate of the percentage OM content (Robertson \& Taylor, 2007).
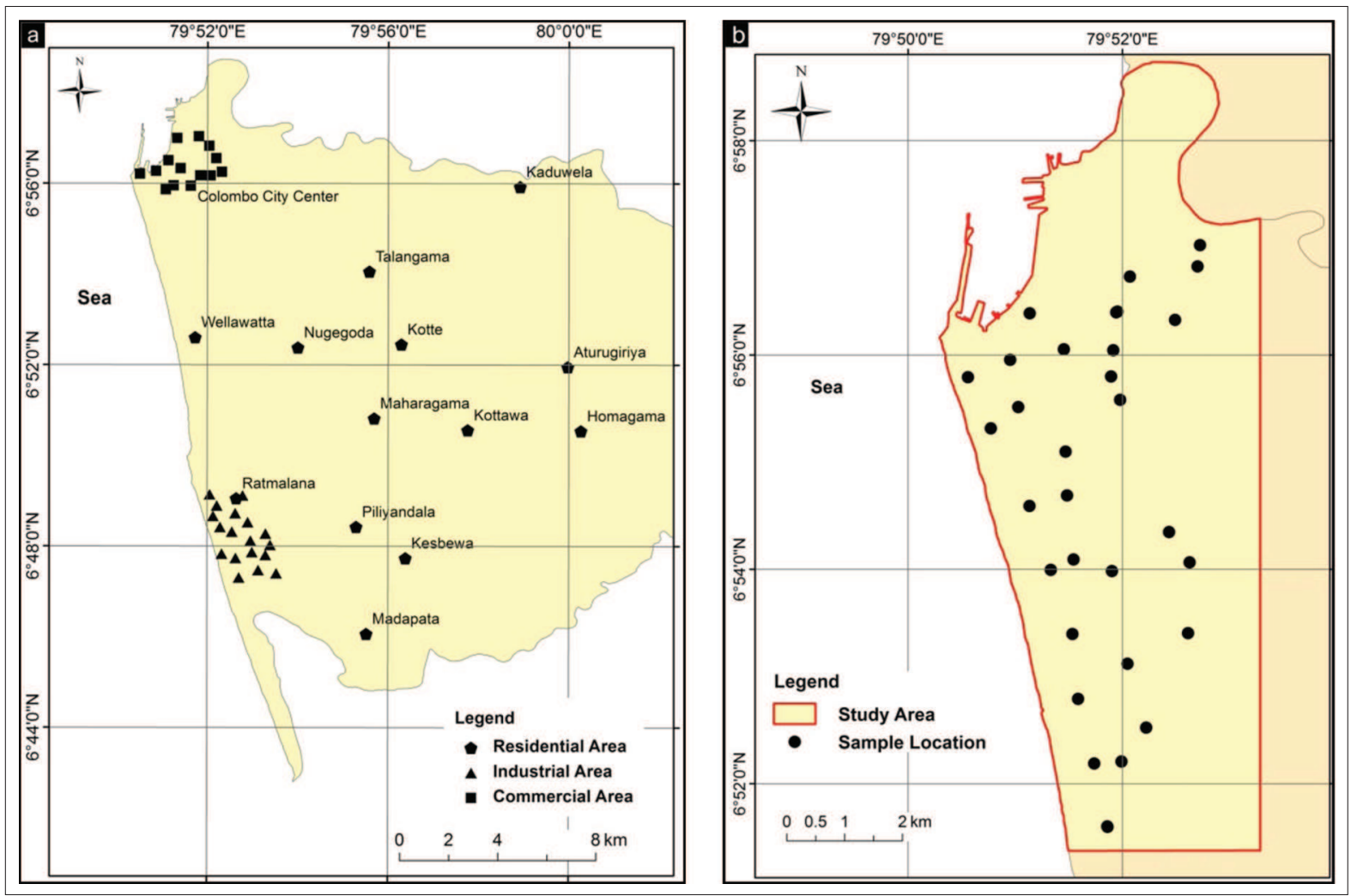

Figure 1: Study area showing sampling locations of (a) RDS and (b) road dust 
Acid digestion of $0.1 \mathrm{~g}$ of sieved samples was done by the microwave digestion method (Wei et al., 2010) at the National Institute of Fundamental Studies, Kandy, Sri Lanka using $\mathrm{HNO}_{3}, \mathrm{HClO}_{4}$ and $\mathrm{HF}\left(\mathrm{HNO}_{3}: \mathrm{HClO}_{4}\right.$ : $\mathrm{HF}=7: 2: 1$ ). The concentrations of $\mathrm{Cu}, \mathrm{Zn}, \mathrm{Pb}, \mathrm{Cr}, \mathrm{Fe}$ and $\mathrm{Mn}$ in acid digested samples were measured by flame atomic absorption spectrophotometry (AAS, Varian AA240FS) at the Department of Geology, University of Peradeniya, Sri Lanka. The accuracy of determination was controlled by means of duplicates, reagent blanks and reference materials. Analysis errors were maintained below $5-10 \%$.

\section{Statistical analysis}

\section{Enrichment factor $(E F)$}

Enrichment factors (EF) for mean metal concentration in sediments and dusts at all the sites were calculated by the following formula:

$E F=\frac{\left(\frac{X}{F e}\right) \text { Sediments }}{\left(\frac{X}{F e}\right) \text { Crust }}$

where, $X$ is the metal studied and $X / \mathrm{Fe}$ is the ratio of the concentration of element $X$ to iron. Iron was chosen as the element of normalisation because natural sources (98\%) vastly dominate its input (Tippie, 1984). The crustal abundance data from literature (Wedepohl, 1995) were used for all EF values.

\section{Geoaccumulation index $\left(I_{g e d}\right)$}

$I_{\text {geo }}$ has been exploited to evaluate the degree of pollution by heavy metals in sediments (Hoque et al., 2011). $I_{\text {geo }}$ can be calculated by the following formula:

$I_{\text {geo }}=\log _{2}\left(\frac{C n}{1.5 B n}\right)$

where $C n$ is the concentration of the examined metal in the sediment, $B n$ is the geochemical background value of the concentration of a given metal in the area [data obtained by Dissanayake (1987) were used as the background values], and 1.5 is the background matrix correction factor. The factor 1.5 is used for possible variation in the background due to lithogenic effects (Hoque et al., 2011). The following classification is given for the index of geoaccumulation (Förstner et al., 1990) and inferences can be drawn accordingly:
$<0$ Practically unpolluted

0 - 1 Unpolluted to moderately polluted

$1-2$ Moderately polluted

2 - 3 Moderately to strongly polluted

$3-4$ Strongly polluted

$4-5$ Strongly to very strongly polluted

$>5$ Very strongly polluted

\section{Spatial analysis}

Heavy metal concentration data were used as input data for a grid-based contouring map to study the distribution of measured metals in road dust. The software used for the geochemical mapping was Arc GIS 10.0. The geostatistical interpolation method called Inverse Distance Weighted (IDW) was adopted for the interpolation of geographical data.

\section{RESULTS AND DISCUSSION}

\section{Total organic matter content}

The results show that the total OM content in RDS increases in the order of industrial $<$ commercial $<$ residential area (Table 1) within a range of $1.4-21.7 \%$. All these values are relatively higher than the values measured from some cities in the UK and Eastern China (Robertson \& Taylor, 2007; Zhu et al., 2008). The average value of total OM content in road dust in the commercial area is $9 \%$ with a range of $4-30 \%$. The range of OM content of the dust in other areas is from $1.1-13.7 \%$ with an average of $4.2 \%$.

Table 1: Total OM content in RDS and road dust

\begin{tabular}{lcccc}
\hline Sample type & Area & $\begin{array}{c}\text { Organic } \\
\text { matter } \%\end{array}$ & Range & SD \\
\hline RDS & Industrial & 5.8 & $1.4-17.8$ & 4.4 \\
& Commercial & 9.4 & $3.0-15.9$ & 3.7 \\
& Residential & 12.4 & $4.1-21.7$ & 6.1 \\
Road dust & Commercial & 9 & $4.0-30.3$ & 5.6 \\
& Other areas & 4.2 & $1.1-13.7$ & 4.1 \\
\hline
\end{tabular}

There are anthropogenic as well as natural sources for the OM present in the studied environment. Vehicle tires and incompletely burned fossil fuel act as the main anthropogenic sources for OM in the area, which was clearly indicated by the elevated OM content in the samples collected close to the road junctions and traffic light areas where traffic was more likely to undergo 
stop-start maneuvers. Peaty soil patches, which are predominant in the area (Dissanayake, 1987) may also contribute to the OM content in the dust. The OM content in an area is important because it provides binding sites for metal ions, increasing accumulation, which simultaneously increases metal toxicity. Similarly, OM influences metal bioavailability by easily discharging bounded metal particles into the environment (Ongeri et al., 2010).

\section{Heavy metal concentrations}

The most abundant element in the RDS samples is Fe, which is in the range of $25,321-55,196 \mathrm{mg} / \mathrm{kg}$ (Table 2). $\mathrm{Cu}, \mathrm{Pb}$ and $\mathrm{Cr}$ show the highest concentrations in industrial areas, while $\mathrm{Zn}$ and $\mathrm{Mn}$ are high in commercial areas for RDS. $\mathrm{Zn}, \mathrm{Cu}, \mathrm{Mn}$ and Fe content in the RDS samples are significantly higher compared to the background levels (Dissanayake, 1987). This indicates that anthropogenic processes contaminate the urban environment with heavy metals. Although the measured values are not high as in the other cities studied in the world (Birch \& Scollen, 2003; Robertson \& Taylor, 2007; Zhu et al., 2008), it can be assumed that the rate of accumulation of heavy metals in the study area is considerably high. This is due to the fact that the urbanisation of the study area has taken place in the recent past unlike the other studied cities, which have a long metropolitanised history.

One of the sources of Fe in RDS may be the basement soil as the area is covered mainly by lateritic soil (Dissanayake, 1987). Due to nearby ocean, metal corrosion in the area is also high (Nunez et al., 2005). Therefore, such corroded particles can directly accumulate into RDS through surface runoff. A relatively low Fe concentration in road dust indicates that the lithological component of road dust is less than for RDS. Other than that, road dust generally contains finer particles than RDS (Birch \& Scollen, 2003), therefore coarser soil particles containing $\mathrm{Fe}$ in sediments or in soil are not resuspended.

Other than $\mathrm{Fe}$, the $\mathrm{Zn}$ concentration in RDS is also relatively high. Elevated $\mathrm{Zn}$ concentrations, particularly along the main roads, may come from traffic sources, specially from vehicle tires as they are subjected to wear and tear ( $\mathrm{Li}$ et al., 2001). $\mathrm{Pb}$ pollution in street dust is likely caused by $\mathrm{Pb}$ particles from vehicle emissions (Kim et al., 1998; Ahmed \& Ishiga, 2006).

The metal concentrations of the other two areas vary widely. Higher $\mathrm{Zn}$ and $\mathrm{Cr}$ concentration in these areas may be due to contamination by paints, building materials and vehicle parts (Alloway \& Alloway,



Journal of the National Science Foundation of Sri Lanka 44(2)

June 2016 
1995; Ahmed \& Ishiga, 2006). This indicates the input of dust particles from construction processes and the miscalculation that it imposes on data.

Except for Fe, all the other metals are higher in road dust samples than in RDS samples. At coastal cities, the composition of airborne particles is affected by marine aerosols (Adamo et al., 2008). Due to its close proximity to the ocean, the city is subjected to wind flows from the direction of the sea. This can resuspend the dust particles and distribute them over the whole area preventing their accumulation along the edges of the roads. Also, soil from the poorly constructed pavements may also mix with the dust particles and dilute the metal concentration in RDS. Road dust goes through a winnowing process with lighter components blowing away, while the heavier particles settle out. Similarly grinding process from tires rolling over the dust will also accumulate heavier particles, while the RDS does not experience such effect much.

Although urbanisation and industrialisation have been proceeding rapidly in the CMR during the last few decades, city-based activities are low compared to the large cities of the world. However, the accumulated $\mathrm{Cu}$ levels in samples are comparable with the other studied cities (Figures 2a and 2b). $\mathrm{Zn}$ and $\mathrm{Pb}$ concentrations of all the samples are characteristically low in sediments.

\section{Possible sources for heavy metals}

A significant positive correlation was observed for $\mathrm{Fe}$ with $\mathrm{Zn}, \mathrm{Mn}$ and $\mathrm{Cu}$ in RDS (Table 3). However, none of the measured elements show any correlation

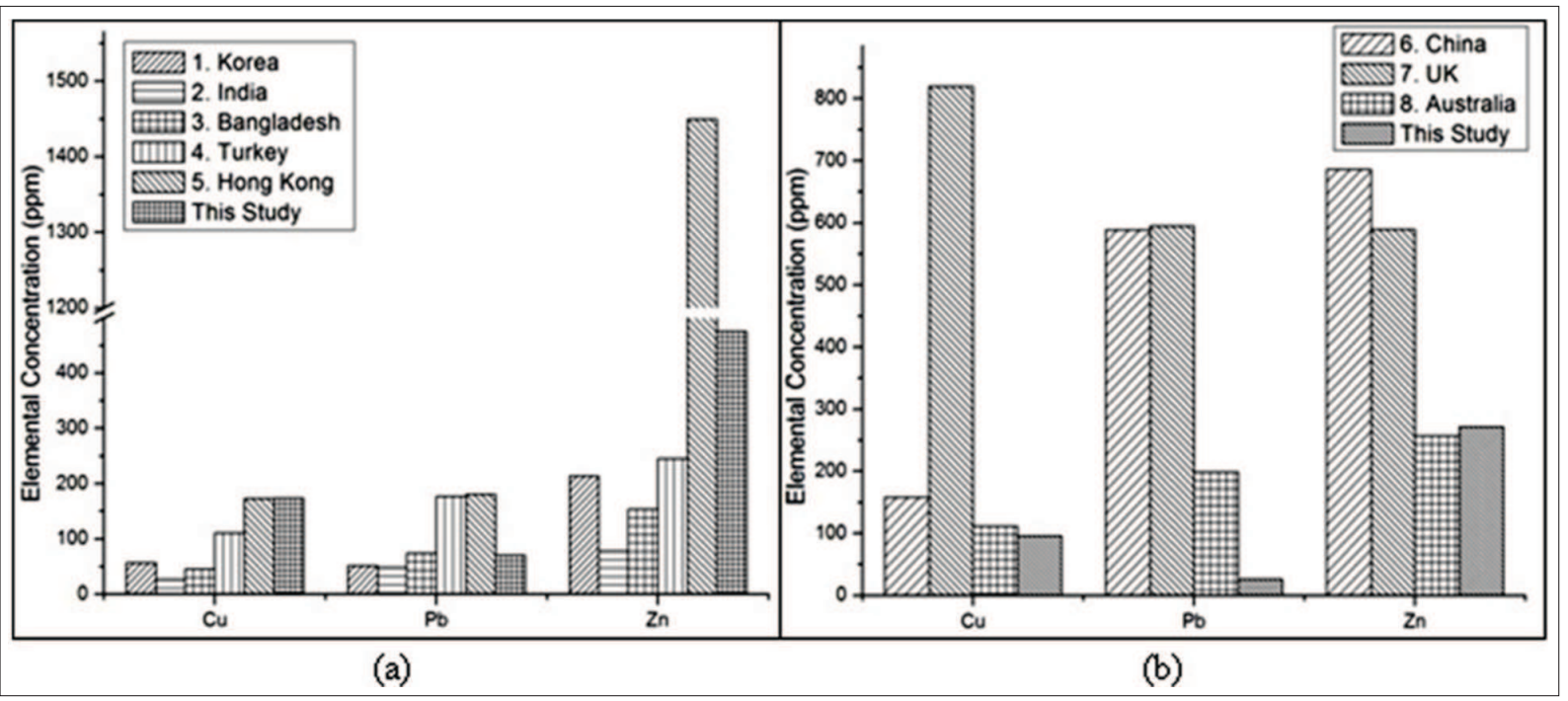

Figure 2: Comparison of elemental concentration in (a) road dust and (b) RDS samples collected from three different parts of the world with this study.

${ }^{1} \mathrm{Kim}$ et al. (1998); ${ }^{2} \mathrm{Singh}$ (2009); ${ }^{3} \mathrm{Ahmed}$ and Ishiga (2006); ${ }^{4} \mathrm{Kabadayi}$ and Cesur (2010); ${ }^{5} \mathrm{Li}$ et al. (2001); ${ }^{6} \mathrm{Zhu}$ et al. (2008); ${ }^{7}$ Robertson and Taylor (2007); ${ }^{8}$ Brich and Scollen (2003)

Table 3: Pearson's correlation coefficients of measured elements and OM content of RDS

\begin{tabular}{lccccccc}
\hline & $\mathrm{Zn}$ & $\mathrm{Cu}$ & $\mathrm{Pb}$ & $\mathrm{Fe}$ & $\mathrm{Mn}$ & $\mathrm{Cr}$ & $\mathrm{OM}$ \\
\hline $\mathrm{Zn}$ & 1.0 & & & & & & \\
$\mathrm{Cu}$ & 0.5 & 1.0 & & & & & \\
$\mathrm{~Pb}$ & 0.1 & 0.1 & 1.0 & & & & \\
$\mathrm{Fe}$ & 0.6 & 0.7 & 0.0 & 1.0 & & & \\
$\mathrm{Mn}$ & 0.4 & 0.4 & -0.1 & 0.7 & 1.0 & & \\
$\mathrm{Cr}$ & -0.2 & 0.1 & 0.1 & 0.4 & 0.2 & 1.0 & \\
$\mathrm{OM}$ & 0.2 & 0.2 & 0.2 & 0.2 & 0.2 & 0.1 & 1.0 \\
\hline
\end{tabular}

Table 4: Pearson's correlation coefficients of measured elements and $\mathrm{OM}$ content of road dust

\begin{tabular}{lccccccc}
\hline & $\mathrm{Zn}$ & $\mathrm{Cu}$ & $\mathrm{Pb}$ & $\mathrm{Fe}$ & $\mathrm{Mn}$ & $\mathrm{Cr}$ & $\mathrm{OM}$ \\
\hline $\mathrm{Zn}$ & 1.0 & & & & & & \\
$\mathrm{Cu}$ & 0.2 & 1.0 & & & & & \\
$\mathrm{~Pb}$ & 0.3 & 0.5 & 1.0 & & & & \\
$\mathrm{Fe}$ & 0.0 & 0.3 & 0.1 & 1.0 & & & \\
$\mathrm{Mn}$ & 0.7 & 0.0 & 0.2 & 0.2 & 1.0 & & \\
$\mathrm{Cr}$ & 0.5 & 0.1 & 0.6 & -0.1 & 0.6 & 1.0 & \\
$\mathrm{OM}$ & -0.2 & -0.4 & 0.1 & -0.6 & -0.3 & 0.2 & 1.0 \\
\hline
\end{tabular}


with the content of OM in the samples. In road dust, $\mathrm{Mn}$ correlates well with $\mathrm{Zn}$ and $\mathrm{Cr}$. Also $\mathrm{Cr}$ correlates well with $\mathrm{Pb}$ (Table 4). In contrast to RDS, Fe does not correlate well with the other elements of dust but it shows a negative correlation with the OM content. These strong correlations indicate that the metals in the area may have originated from a common source (Guney et al., 2010).

Strong correlation between $\mathrm{Fe}, \mathrm{Zn}$ and $\mathrm{Cu}$ in $\mathrm{RDS}$ may arise due to their usage in metal industry, specially in galvanisation (Alloway \& Alloway, 1995), while the correlation between Fe and Mn can be attributed to the chemical similarities between these two elements (Guney et al., 2010). In road dust, Fe does not correlate well with $\mathrm{Zn}$ or $\mathrm{Cu}$ reconfirming the low input of Fe in road dust. The significant correlation of $\mathrm{Cr}$ with $\mathrm{Zn}$ and $\mathrm{Pb}$ may be due to the use of $\mathrm{Cr}$ together with $\mathrm{Zn}$ and $\mathrm{Pb}$ in metal alloys (Alloway \& Alloway, 1995), while $\mathrm{Cr}$ and $\mathrm{Mn}$ correlation can be due to their chemical similarities.

Previous studies from other parts of the world showed that many metal pairs in urban dust and RDS are correlated positively, and the relationship was used to interpret the source of heavy metals in the samples (Guney et al., 2010; Kabadayi \& Cesur, 2010; Singh, 2011). Contrastingly in the CMR, elements do not show strong positive correlations, which indicates that complex behaviours of source materials and processes of accumulation are present. Differences due to locations of anthropogenic activities, traffic characteristics, road condition and texture, position of the samples within traffic lane and recent rain are some of the factors that control the level of contamination.

\section{Assessment of heavy metal pollution}

Enrichment factors (EF) for mean metal concentration in RDS and road dust are given in Table 5. EFs at all the sampling sites are higher than 1 and the EF for road dust is higher than RDS. An element having a high EF can easily be released into the environment from the sediments, thus contributing to their bioavailability (Hoque et al., 2011). Apart from Mn, which is not a highly toxic metal all the other elements indicated slightly higher EFs indicating that there is a possible threat of releasing these elements into the environment. Contrastingly, very high EF values were obtained for road dust samples showing that there is a high possibility for the release of these elements to the environment. These high EF values together with high concentrations in road dust pose a great threat of pollutant contamination.
Table 5: Enrichment factors of RDS samples and road dust

\begin{tabular}{lcccccc}
\hline Sample type & Area & $\mathrm{Zn}$ & $\mathrm{Cu}$ & $\mathrm{Cr}$ & $\mathrm{Mn}$ & $\mathrm{Pb}$ \\
\hline RDS & Residential & 4.8 & 4 & 2 & 0.3 & N/A \\
& Commercial & 6.9 & 7.9 & 2 & 0.8 & 1.2 \\
& Industrial & 4.0 & 7.6 & 2.9 & 0.7 & 1.8 \\
\multirow{2}{*}{ Road dust } & Commercial & 12.7 & 17.3 & 6.7 & 1.3 & 5.8 \\
\hline
\end{tabular}

According to the geoaccumulation index, the Colombo city is unpolluted to moderately polluted in terms of all the measured elements in RDS, with relatively higher $I_{g e o}$ values in commercial and industrial areas (Table 6). Further, road dust was moderate to strongly polluted in terms of $\mathrm{Zn}, \mathrm{Cu}$ and $\mathrm{Mn}$. High $I_{\text {geo }}$ values in commercial areas show that commercial activities play a major role in environmental pollution in the area.

Table 6: Geoaccumulation index values of RDS and road dust

\begin{tabular}{lccccc}
\hline Sample type & Area & $\mathrm{Zn}$ & $\mathrm{Cu}$ & $\mathrm{Cr}$ & $\mathrm{Mn}$ \\
\hline RDS & Commercial & 1.8 & 1.8 & 0.1 & 1.8 \\
& Industrial & 1.1 & 1.8 & 0.7 & 1.7 \\
& Residential & 1.3 & 0.9 & 0.2 & 0.4 \\
Road dust & Commercial & 2.4 & 2.5 & 1.4 & 2.1 \\
\hline
\end{tabular}

\section{Heavy metal distribution with respect to the sources of dust}

Only the dust samples collected from the commercial area were considered for the grid-based contouring maps since the samples from other areas show highly variable values, which may be due to the input from construction activities on the chemistry of dust. Spatial distribution maps show higher accumulation of measured elements towards the North and Northwestern parts of the study area, except for Fe (Figure 3). The central bus stand and the railway station of the Colombo Capital are located in the Northwestern part of the study area. The main port of the country is also situated in the same direction. This indicates that transportation related-activities are the dominant source of heavy metals in the CMR. Further, there are several elevated concentration points scattered over the area, which may be due to point sources. However, the Fe concentration does not follow a similar pattern. It also confirms that the $\mathrm{Fe}$ in basement soil may mask the anthropogenically-derived Fe in dust. 

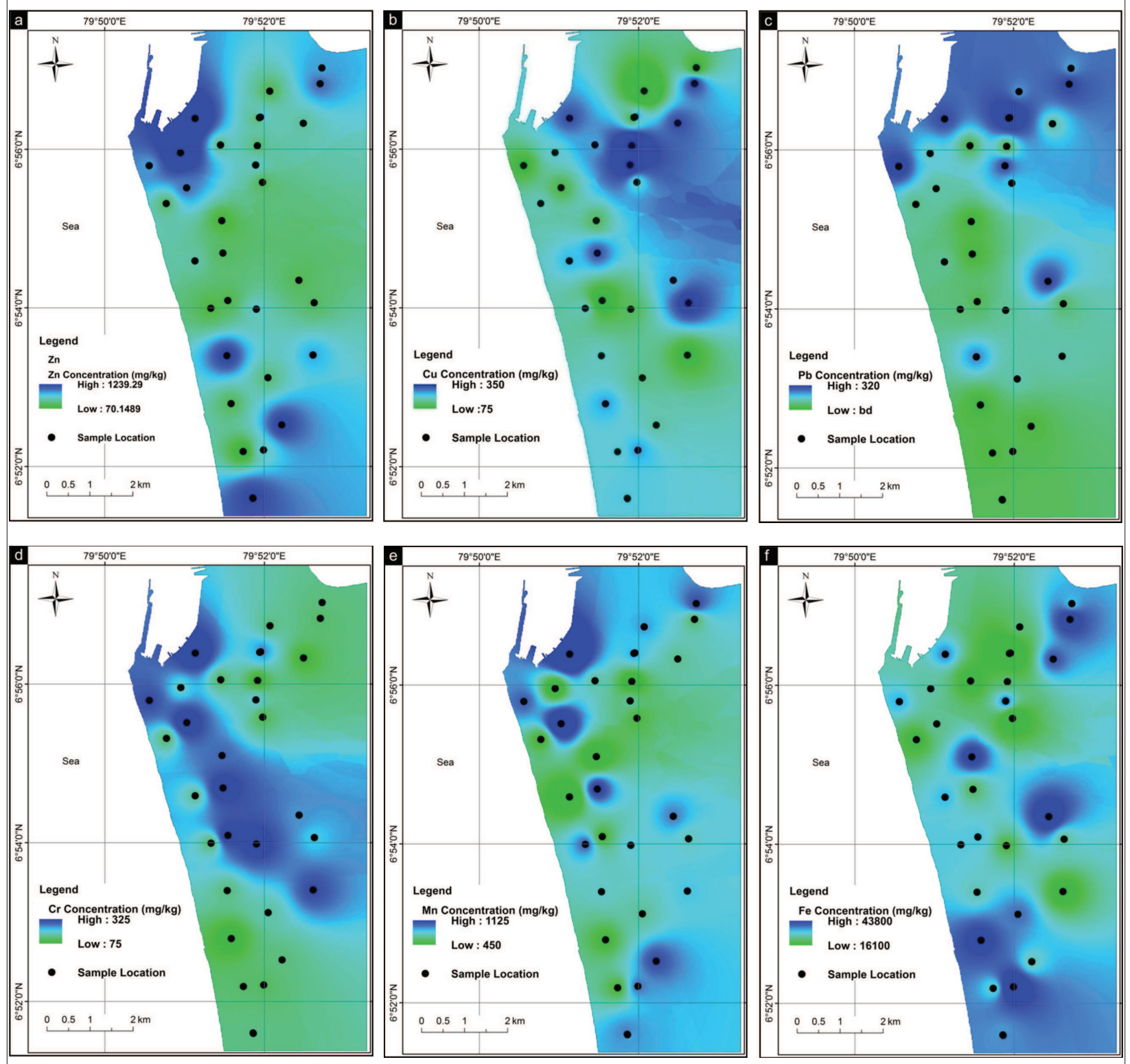

Figure 3: Maps showing spatial distribution of measured elements in dust

The wind flow into the city varies depending on monsoonal conditions but mainly flows from the ocean and moves across the city towards the interior parts of the country. Wind flowing from the ocean removes road surface dust before accumulation so that most of the heavy metal concentrations along the western coast of the study area are low despite the traffic densities being equal.

More than $20 \%$ of the vehicles in the city are older than 25 years (Department of Census and Statistics, 2011). These vehicles could be the main source of OM and heavy metals, since they exhaust more organic compounds, which contribute to air pollution by emitting over $10-15 \%$ of the fuel in an unburnt form. Other than this, tire tread which contains heavy metals such as $\mathrm{Mn}, \mathrm{Fe}$, $\mathrm{Co}, \mathrm{Ni}, \mathrm{Cu}, \mathrm{Zn}, \mathrm{Cd}$, and $\mathrm{Pb}$, and tire dust contribute some of these elements in the form of airborne dust (Adachi \& Tainosho, 2004). Although large scale industries are few in the area (Senarath, 2003), pollution in the industriallyactive region is high. This is mainly due to unfriendly environmental practices common to developing countries such as poor waste management systems, unorganised drainage network and release of untreated industrial waste into the environment. 
Except for anthropogenic sources and basement soils, natural conditions of an area such as morphology and wind patterns also affect the pollutant content in RDS and road dust. Hence, when considering precautionary measures and pollution control methods in an urban area, both anthropogenic and natural conditions have to be considered.

\section{CONCLUSION}

Although industrial activities are not dominant in the CMR, elevated concentrations of heavy metals in RDS were observed from the area with small scale industries, and it may be due to poor industrial waste management. In contrast to RDS, road dust is characterised by elevated concentrations of heavy metals. Further, it appears that traffic-related activities are the major source for the contamination of dust.

According to the geoaccumulation index, road dust is moderately to strongly polluted and RDS are moderately polluted in terms of $\mathrm{Zn}$ and $\mathrm{Cu}$. Further, as indicated by the enrichment factor, measured elements tend to enrich in road dust than in RDS.

\section{Acknowledgement}

This work was financially supported by the National Research Council, Sri Lanka (Grant No.: NRC-11-142). The Institute of Fundamental Studies, Kandy is gratefully acknowledged for the laboratory facilities provided.

\section{REFERENCES}

1. Adachi K. \& Tainosho Y. (2004). Characterization of heavy metal particles embedded in tire dust. Environment International 30: 1009 - 1017.

DOI: http://dx.doi.org/10.1016/j.envint.2004.04.004

2. Adamo P., Giordano S., Naimo D. \& Bargagli R. (2008). Geochemical properties of airborne particulate matter (PM10) collected by automatic device and biomonitors in a Mediterranean urban environment. Atmospheric Environment 42: 346 - 357.

DOI: http://dx.doi.org/10.1016/j.atmosenv.2007.09.018

3. Ahmed F., Bibi M.H. \& Ishiga H. (2007). Environmental assessment of Dhaka City (Bangladesh) based on trace metal contents in road dusts. Environmental Geology 51: $975-985$.

DOI: http://dx.doi.org/10.1007/s00254-006-0367-1

4. Ahmed F. \& Ishiga H. (2006). Trace metal concentrations in street dusts of Dhaka City, Bangladesh. Atmospheric Environment 40: 3835 - 3844.

DOI: http://dx.doi.org/10.1016/j.atmosenv.2006.03.004
5. Alloway B.J. \& Alloway B. (1995). Heavy Metals in Soils, pp. 613. Springer, The Netherlands.

6. Birch G. \& Scollen A. (2003). Heavy metals in road dust, gully pots and parkland soils in a highly urbanised sub-catchment of Port Jackson, Australia. Soil Research 41: $1329-1342$. DOI: http://dx.doi.org/10.1071/SR02147

7. Bruni B., Pacella A., MazziottiTagliani S., Gianfagna A. \& Paoletti L. (2006). Nature and extent of the exposure to fibrous amphiboles in Biancavilla. Science of the Total Environment 370: 9 - 16.

DOI: http://dx.doi.org/10.1016/j.scitotenv.2006.05.013

8. Cooray P. (1984). An Introduction to the Geology of Sri Lanka (Ceylon), pp. 340. National Museums of Sri Lanka Publication. Department of National Museums, P.O. Box 854, Sir Marcus Fernando Mawatha, Colombo 07, Sri Lanka.

9. De Alwis P., Ariyaratna S., Azmy S. \& Dassanayaka N. (1994). Environmental pollution and its impact on fishery management in Lunawa Lagoon. Proceedings of the Sri Lanka National Workshop on Development of Community-Based Fishery Management. Colombo, Sri Lanka, pp. 200 - 208.

10. Department of Census and Statistics (2011). Available at http://www.statistics.gov.lk/PopHouSat/CPH2011/Pages/ Activities/Reports/FinalReport/FinalReport.pdf, Accessed 1 January 2015.

11. Department of Meteorology (2013). Available at http:// www. meteo.gov.lk/index.php?option $=$ com_content $\&$ vie $w=$ article $\& i d=13 \&$ Itemid $=132 \&$ lang $=e n$, Accessed 1 January 2015.

12. Dissanayake C. (1987). Metals in a lateritic peat deposit - a case study from Sri Lanka. Chemical Geology 60: $137-143$.

13. Elangasinghe M. \& Shanthini R. (2009). Determination of atmospheric PM 10 concentration in Kandy in relation to traffic intensity. Journal of the National Science Foundation of Sri Lanka 36: 245 - 249.

14. Förstner U., Ahlf W., Calmano W. \& Kersten M. (1990). Sediment criteria development, contributions from environmental geochemistry to water quality management. Sediments and Environmental Geochemistry (eds. D. Heling, P. Rothe, U. Forstner \& P. Stoffers), pp. 311 - 338. Springer, Hidelberg, Germany.

15. Guney M., Onay T.T. \& Copty N.K. (2010). Impact of overland traffic on heavy metal levels in highway dust and soils of Istanbul, Turkey. Environmental Monitoring and Assessment 164: 101 - 110 .

DOI: http://dx.doi.org/10.1007/s10661-009-0878-9

16. Hoque R.R., Goswami K., Kusre B. \& Sarma K. (2011). Distribution and solid-phase speciation of toxic heavy metals of bed sediments of Bharali tributary of Brahmaputra River. Environmental Monitoring and Assessment 177: $457-466$.

DOI: http://dx.doi.org/10.1007/s10661-010-1647-5

17. Ileperuma O. (2000). Environmental pollution in Sri Lanka: a review. Journal of the National Science Foundation of Sri Lanka 28: $301-325$. 
18. Kabadayi F. \& Cesur H. (2010). Determination of $\mathrm{Cu}$, $\mathrm{Pb}, \mathrm{Zn}, \mathrm{Ni}, \mathrm{Co}, \mathrm{Cd}$, and $\mathrm{Mn}$ in road dusts of Samsun City. Environmental Monitoring and Assessment 168: 241 - 253. DOI: http://dx.doi.org/10.1007/s10661-009-1108-1

19. Kim K.W., Myung J.H., Ahn J. \& Chon H.T. (1998). Heavy metal contamination in dusts and stream sediments in the Taejon area, Korea. Journal of Geochemical Exploration 64: $409-419$.

20. Kumarage A.S. (2007). Impacts of transportation infrastructure and services on urban poverty and land development in Colombo, Sri Lanka. Global Urban Development Magazine 3(1). Available at http://www. globalurban.org/GUDMag07Vol3Iss 1/Kumerage\%20PDF. $p d f$

21. Li X., Poon C.S. \& Liu P.S. (2001). Heavy metal contamination of urban soils and street dusts in Hong Kong. Applied Geochemistry 16: 1361 - 1368.

22. Lu S. \& Bai S. (2010). Contamination and potential mobility assessment of heavy metals in urban soils of Hangzhou, China: relationship with different land uses. Environmental Earth Sciences 60: 1481 - 1490. DOI: http://dx.doi.org/10.1007/s12665-009-0283-2

23. Mostafa A., Hegazi A., El-Gayar M.S. \& Andersson J. (2009). Source characterization and the environmental impact of urban street dusts from Egypt based on hydrocarbon distributions. Fuel 88: $95-104$.

DOI: http://dx.doi.org/10.1016/j.fuel.2008.08.006

24. Nunez L., Reguera E., Corvo F., Gonzalez E. \& Vazquez C. (2005). Corrosion of copper in seawater and its aerosols in a tropical island. Corrosion Science 47: $461-484$. DOI: http://dx.doi.org/10.1016/j.corsci.2004.05.015

25. Ongeri D., Lalah J. \& Wandiga S. (2010). Speciation of Cd, $\mathrm{Cu}, \mathrm{Zn}, \mathrm{Fe}$ and $\mathrm{Pb}$ in sediments sampled from Lake Victoria basin, Kenya. The Environmentalist 30: 254 - 259. DOI: http://dx.doi.org/10.1007/s10669-010-9269-6

26. Pitawala A., Herath D. \& Piyatunga N. (2013). Chemical characterization of household dust in two major cities: Colombo, the capital and Kandy, the hill capital, Sri Lanka. Carpathian Journal of Earth and Environmental Sciences 8: $89-95$.

27. Ray S., Khillare P., Agarwal T. \& Shridhar V. (2008). Assessment of PAHs in soil around the International Airport in Delhi, India. Journal of Hazardous Materials 156: $9-16$.

DOI: http://dx.doi.org/10.1016/j.jhazmat.2007.11.099

28. Robertson D.J. \& Taylor K.G. (2007). Temporal variability of metal contamination in urban roaddeposited sediment in Manchester, UK: implications for urban pollution monitoring. Water, Air, and Soil Pollution
186: $209-220$.

DOI: http://dx.doi.org/10.1007/s11270-007-9478-x

29. Senarath C. (2003). An overview of air pollution and respiratory illnesses in Sri Lanka. Proceedings of the Third International Conference on Environment and Health (eds. M.J. Bunch, V.M. Suresh \& T.V. Kumaran), University of Madras and Faculty of Environmental Studies, Chennai, India, pp. $489-501$.

30. Seneviratne M., Mahawatte P., Fernando R., Hewamanna R. \& Sumithrarachchi C. (1999). A study of air particulate pollution in Colombo using a nuclear-related analytical technique. Biological Trace Element Research 71: 189 - 194.

DOI: http://dx.doi.org/10.1007/BF02784204

31. Singh A.K. (2011). Elemental chemistry and geochemical partitioning of heavy metals in road dust from Dhanbad and Bokaro regions, India. Environmental Earth Sciences 62: $1447-1459$.

DOI: http://dx.doi.org/10.1007/s12665-010-0630-3

32. Tippie V. (1984). Environmental characterization of Chesapeake Bay and a framework for action. The Estuary as a Filter (ed. V. Kennedy), pp. 467 - 487. Academic Press, New York, USA.

DOI: http://dx.doi.org/10.1016/B978-0-12-405070-9.50028-1

33. Tume P., Bech J., Sepulveda B., Tume L. \& Bech J. (2008). Concentrations of heavy metals in urban soils of Talcahuano (Chile): a preliminary study. Environmental Monitoring and Assessment 140: 91 - 98.

DOI: http://dx.doi.org/10.1007/s10661-007-9850-8

34. Wedepohl K.H. (1995). The composition of the continental crust. Geochimica et Cosmochimica Acta 59(7): $1217-1232$.

35. Wei B., Jiang F., Li X. \& Mu S. (2010). Heavy metal induced ecological risk in the city of Urumqi, NW China. Environmental Monitoring and Assessment 160: 33 - 45. DOI: http://dx.doi.org/10.1007/s10661-008-0655-1

36. Wei B. \& Yang L. (2010). A review of heavy metal contaminations in urban soils, urban road dusts and agricultural soils from China. Microchemical Journal 94: $99-107$.

DOI: http://dx.doi.org/10.1016/j.microc.2009.09.014

37. Whittaker A., Jones T., Shao L., Shi Z., BéruBé K. \& Richards R. (2003). Mineral dust in urban air: Beijing, China. Mineralogical Magazine 67: 173 - 182.

DOI: http://dx.doi.org/10.1180/0026461036720111

38. Zhu W., Bian B. \& Li L. (2008). Heavy metal contamination of road-deposited sediments in a medium size city of China. Environmental Monitoring and Assessment 147: $171-181$.

DOI: http://dx.doi.org/10.1007/s10661-007-0108-2 